University of Nebraska - Lincoln

DigitalCommons@University of Nebraska - Lincoln

U.S. Environmental Protection Agency Papers

U.S. Environmental Protection Agency

2009

\title{
Artificial insemination in South American camelids and wild equids
}

G. P. Adams

University of Saskatchewan, Saskatoon SK S7N 5B4, Canada

M. H. Ratto

Faculty of Veterinary Sciences, Universidad Austral de Chile, Valdivia, Chile

C. W. Collins

Center for Species Survival, Smithsonian's National Zoological Park, Front Royal, VA, USA

D. R. Bergfelt

Environmental Protection Agency, Office of Science Coordination and Policy, Washington, DC, USA

Follow this and additional works at: https://digitalcommons.unl.edu/usepapapers

Part of the Civil and Environmental Engineering Commons

Adams, G. P.; Ratto, M. H.; Collins, C. W.; and Bergfelt, D. R., "Artificial insemination in South American camelids and wild equids" (2009). U.S. Environmental Protection Agency Papers. 7.

https://digitalcommons.unl.edu/usepapapers/7

This Article is brought to you for free and open access by the U.S. Environmental Protection Agency at DigitalCommons@University of Nebraska - Lincoln. It has been accepted for inclusion in U.S. Environmental Protection Agency Papers by an authorized administrator of DigitalCommons@University of Nebraska - Lincoln. 


\title{
Artificial insemination in South American camelids and wild equids
}

\author{
G.P. Adams ${ }^{\mathrm{a}, *}$, M.H. Ratto ${ }^{\mathrm{b}}$, C.W. Collins ${ }^{\mathrm{c}}$, D.R. Bergfelt ${ }^{\mathrm{d}}$ \\ ${ }^{a}$ Department of Veterinary Biomedical Sciences, Western College of Veterinary Medicine, 52 Campus Drive, University of Saskatchewan, \\ Saskatoon SK S7N 5B4, Canada \\ ${ }^{\mathrm{b}}$ Faculty of Veterinary Sciences, Universidad Austral de Chile, Valdivia, Chile \\ ${ }^{\mathrm{c}}$ Center for Species Survival, Smithsonian's National Zoological Park, Front Royal, VA, USA \\ ${ }^{\mathrm{d}}$ Environmental Protection Agency, Office of Science Coordination and Policy, Washington, DC, USA
}

\begin{abstract}
An overview of the present status of the use of artificial insemination (AI) in South American camelids and wild equids is offered. Technical aspects of semen collection, dilution and cryopreservation have limited the development and use of AI in camelid and equid species. To-date, efficiency is low but progress has been made and viable offspring have been produced through the use of AI in domestic South American camelids using both fresh and frozen semen. The origin, composition, and function of the viscous component of camelid seminal plasma remain a mystery and an obvious area for future research. A better understanding of the normal constituents of seminal plasma will enable the rational design of semen extenders suitable for camelids. Post-thaw sperm viability is very low, and studies are needed to address questions of optimal freezing and thawing procedures as well as the insemination dose. The basis for differences in reported pregnancy rates with sexed and frozen semen in domestic equids, and the ultimate success of AI in wild equids will require continued research into the "stallion effect", extenders and cryoprotectants, optimal volume and number of spermatozoa, temperatures during handling, processing an transport, and insemination techniques. In both camelids and equids, research on domestic species under controlled conditions provides and excellent opportunity to develop effective semen handling techniques for application in wild and endangered species of the respective families.

(C) 2008 Elsevier Inc. All rights reserved.
\end{abstract}

Keywords: artificial insemination; semen; camelids; llamas; alpacas; equids; horse; donkey

\section{Introduction}

Artificial insemination (AI), particularly with frozen semen, has been by far the most effective reproductive technology for selective genetic improvement in farm animal production. The power of this technique for influencing the genetic make-up of a given population is

\footnotetext{
* Corresponding author. Tel.: +1 306966 7411; fax: +1 3069667405 .

E-mail address: gregg.adams@usask.ca (G.P. Adams).
}

exemplified in Holstein cattle, where average milk production has nearly doubled in the span of only $40 \mathrm{y}$. The observation that AI has brought about a measurable narrowing of genetic diversity within the Holstein breed (i.e., rapid selection for a specific production trait) provides support for the notion that if applied for that purpose, AI is equally as effective for preserving and expanding genetic diversity in threatened populations. The potential for successful application of AI in wild camelids and equids, in particular, is high, because the abundance of domesticated camelid and equid populations provide an excellent opportunity for research and 
Table 1

Semen collection methods and characteristics (mean \pm S.E.M. and/or range) in South American camelids.

\begin{tabular}{|c|c|c|c|c|c|}
\hline Species [Ref.] & Method of collection $^{a}$ & Volume-mL (range) & Sperm $\times 10^{6}$ per $\mathrm{mL}$ & $\%$ Motility (range) & $\%$ Normal \\
\hline Alpaca [3] & Vaginal sac & $1.9(0.4-6.6)$ & 33.0 & Low & 41 \\
\hline Alpaca [9] & Electro-ejac & $(1.1-1.8)$ & $0.001-2.55$ & Low & - \\
\hline Alpaca [13] & AV-dummy & $1.7 \pm 0.2(0.4-4.3)$ & - & 50.0 & - \\
\hline Alpaca [14] & AV-dummy & $(0.6-2.7)$ & $0.09-0.2$ & - & - \\
\hline Alpaca [15] & AV-dummy & $1.9 \pm 0.4(0.8-3.1)$ & $82.5-250$ & $85 \pm 5.2$ & $75.9 \pm 2.1$ \\
\hline Alpaca [16] & AV-dummy & $3.0(1.0-12.5)$ & 600 & - & - \\
\hline Alpaca [17] & AV-dummy & $2.6 \pm 1.8$ & $0.06 \pm 0.03$ & $49.7 \pm 22.6$ & - \\
\hline Alpaca [18] & AV-dummy & - & - & 68.2 & - \\
\hline Alpaca [19] & AV- female & $1.8 \pm 0.8(0.6-3.8)$ & $17.6 \pm 26.1(0.05-92.9)$ & - & $51.0 \pm 12.4$ \\
\hline Alpaca [20] & AV-dummy & $(0.6-8.2)$ & $63-250$ & $55-75$ & $55-75$ \\
\hline Llama [7] & AV- female & $2.4(0.2-6.5)$ & $106.8(15.0-640)$ & $15-50$ & 90.6 \\
\hline Llama [21] & AV-dummy & $3.0 \pm 1.9(0.2-7.9)$ & $1.0 \pm 0.8(0-3.4)$ & $23.7 \pm 20.0(0-65)$ & $39.7 \pm 18.5(0-79.1)$ \\
\hline Llama [22] & AV- female & $3.5 \pm 2.6$ & $85 \pm 89$ & $25-33$ & $32.5 \pm 22.3$ \\
\hline Llama [8] & AV-female & $2.1 \pm 1.4$ & $80 \pm 28$ & $57.6 \pm 22.3$ & - \\
\hline Llama [11] & Electro-ejac & $1.3-4.3$ & $0.0-123.3$ & $0.0-55.5$ & $41.5-81.3$ \\
\hline Vicuna [12] & Electro-ejac & $1.0-2.5$ & $0.01-0.14$ & 10 & $66.0-75.0$ \\
\hline
\end{tabular}

${ }^{\mathrm{a}}$ AV-dummy = artificial vagina within a dummy (phantom) mount; AV-female = artificial vagina and a live receptive female mount.

development. The objective herein is to provide an overview of the current status and potential utility of artificial insemination in South American camelids and wild equids.

\section{South American camelids}

The llama (Lama glama) and alpaca (Vicugna pacos) are domesticated members of the four species of New World camelids. The other two are wild species, the guanaco (Lama guanicoe) and vicuna (Vicugna vicugna), and along with their domestic cousins, inhabit the Andean region of South America from Ecuador to southern Chile. Related Old World camelids include the dromedary (one-humped) and bactrian (two-humped) camels, that inhabit primarily the African and Asian continents, respectively. The International Union for Conservation and Natural Resources (IUCN) lists the vicuna and guanaco as threatened to some degree, and the wild subspecies of Bactrian camel as critically endangered. There appears to be more similarities than differences in the reproductive physiology of Old and New World camelids; however, the following discussion is confined to the latter.

\subsection{Methods of semen collection}

Historically, the inability to consistently collect semen has been one of the most serious impediments to the application of AI in camelids. The challenge stems from the recumbent mating posture in camelids, the duration of copulation (10-60 min in llamas and alpacas), intrauterine deposition of semen, and the viscous nature of the ejaculate [1,2]. Attempts at semen collection in camelids have included the use of condoms or intravaginal sacs, vaginal sponges, electro-ejaculation, post-coital vaginal aspiration, and fistulation of the penile urethra Table 1 . The use of intravaginal sacs [3] was cumbersome, hindered intromission, and was associated with vaginal injury. Similarly, recovery of semen samples from sterile sponges inserted into the cranial vagina before copulation was inefficient and of low quality, and samples were contaminated with blood and epithelial cells [4]. The impact and consequences of the surgical procedure of urethral fistulation [5] have not been evaluated.

The use of an artificial vagina (AV), similar to that used in sheep, was first reported in 1981 [6]. The AV included a coil to simulate the cervix and was mounted inside a dummy that the males were trained to mount. However, the lack of adequate heating equipment required repeated refilling of the hot water chamber to maintain a stable AV temperature during prolonged copulation. The technique was improved with the use of an electric heating pad wrapped around the AV [7]. Collection of semen by an AV mounted inside a dummy is more reliable than other methods and may provide a more physiological sample of semen [6]. An alternative to a dummy mount is the use of a receptive female; the penis of the male can be directed into an AV during the mount $[7,8]$. The disadvantage of semen collection with an $\mathrm{AV}$ is that the males must be trained to serve the $\mathrm{AV}$; perhaps because of prolonged ejaculation, male llamas and alpacas do not serve an AV as readily as bulls and rams. However, consistent results can be obtained once the males become accustomed to the AV with a dummy or live mount. 
Electro-ejaculation was attempted in alpacas more than four decades ago, using a custom-made electroejaculator and applying gradually increasing electrical stimulation (up to $40 \mathrm{~V}$ ) in a periodic fashion (i.e., 4-6 s of stimulation, followed by $4-6 \mathrm{~s}$ of rest) $[9,10]$. From 1.1 to $1.8 \mathrm{~mL}$ of semen was collected, but sperm concentration (range: 1000-255,000 spermatozoa/mL) and quality were extremely variable, and contamination with urine was common. The use of electro-ejaculation in camelid species has since been nearly abandoned, due to inconsistent responses and the need for general anesthesia, but results of a recent study provide reason for reconsideration $[11,12]$. The distance between the prostate and the external anal sphincter was measured using transrectal ultrasonography in male llamas $(n=6)$ and after general anesthesia, the electrodes of an electro-ejaculator probe designed for use in large dogs was placed directly over the prostate gland. Ejaculates were collected from all six males by electro-ejaculation, and samples were larger in volume with a greater percentage of motile sperm compared with semen collected from the same males by AV.

\subsection{Seminal plasma and semen handling}

Effective use of AI requires the dilution and storage of semen, but difficulties in semen collection and handling in llamas and alpacas have been an impediment. The semen of llamas and alpacas is highly viscous $[15,21]$ and as a result, assessment of sperm concentration, morphology, and motility, are difficult. Ejaculates vary in color from nearly clear to milky white, depending on sperm concentration [15,21,23], and a comparatively high proportion of morphologic abnormalities (e.g., 40\%) is common [24]. Unlike the progressive motility of sperm seen in other domestic ruminants, only oscillatory movement is seen in the ejaculate of llamas and alpacas $[13,16]$.

The role of high viscosity of camelid semen is not known, but it may act as a type of sperm reservoir or may be important for maintaining sperm viability within the uterus [25]. To facilitate handling and processing of semen, attempts have been made to liquefy the ejaculate. In a study designed to test the effectiveness of enzymes for liquefying semen (i.e., collagenase, fibrinolysin, hyalurodinase, or trypsin), collagenase was effective in eliminating semen viscosity within $5 \mathrm{~min}$, with little or no influence on sperm characteristics [18]. In a recent study, however, all enzymes effectively reduced viscosity, but satisfactory motility was maintained only with trypsin or papain; i.e., collagenase was toxic at all concentrations [26]. A mechanical technique of liquefying the ejaculate involved alternately aspirating and expelling the ejaculate through a needle; this effectively liquefied the ejaculate and had little influence on other characteristics of semen [27,28].

Only two reports were found regarding the chemical constituents of the seminal plasma of South American camelids - both on alpacas [13,14]. The concentration of components such as chloride, calcium, total proteins, inorganic phosphate, and glucose, were similar to that in other ruminants, but citric acid and fructose concentrations were much lower than that in bulls, horses and pigs - a feature thought to be consistent with the lack of vesicular glands in camelids. Although it is not yet clear whether the sugars act as an energy source for sperm metabolism or as signaling molecules to modulate sperm function (e.g., capacitation), fructose and glucose are routinely incorporated into the majority of extenders for the semen of bulls and rams.

\subsection{AI technique, induction of ovulation and pregnancy rates}

The first attempt at AI in llamas and alpacas [1] involved 42 female alpacas inseminated with fresh undiluted semen obtained from two vicunas and four paco-vicunas (cross between male alpaca and female vicuna). Semen was obtained by electro-ejaculation. Immediately before insemination, the females were mated with vasectomized males to induce ovulation. Semen was deposited in the area of the uterine bifurcation by means of a $35 \mathrm{~cm}$-long plastic catheter, guided transcervically by rectal manipulation. Only one of 42 artificially inseminated females gave birth (Table 2).

Table 2

Results of AI in alpacas and llamas using fresh, non-extended semen.

\begin{tabular}{llll}
\hline Species [Ref.] & Route of insemination & Diagnosed pregnancy rate $(\%)$ & Birth rate $(\%)$ \\
\hline Alpaca [1] & Transcervical & - & $1 / 42(2 \%)$ \\
Alpaca [10] & Transcervical & $27 / 58(46.6 \%)$ & Not reported \\
Alpacas and Llamas [29] & Transcervical & $37 / 94(39 \%)$ & Not reported \\
Alpaca [15] & Transcervical and laparoscopy & $27 / 40(68 \%)$ & Not reported \\
Alpaca [28] & Transcervical & $105 / 207(51 \%)$ & Not reported \\
\hline
\end{tabular}


In subsequent studies, pregnancy rates after AI with fresh raw or extended semen have varied from 39 to $68 \%$ (Table 2), but unfortunately birth rates have not been reported. In a study designed to determine the optimum time for AI after an ovulation-inducing stimulus (i.e., hormone treatment or copulation with a vasectomized male), 96 female alpacas were artificially inseminated $7-45 \mathrm{~h}$ post-stimulus. Fresh, undiluted semen collected by electro-ejaculation was infused transcervically by rectal manipulation or through a vaginal speculum [10] (Table 2). The alpacas were slaughtered $72 \mathrm{~h}$ after $\mathrm{AI}$ and the conception rate was $12,53,43,75$, and $58 \%$ at $7-18 \mathrm{~h}, 19-26 \mathrm{~h}, 27-$ $34 \mathrm{~h}, 35-45 \mathrm{~h}$, and $52 \mathrm{~h}$ after AI, respectively. No differences were observed between groups stimulated to ovulate by hormone treatment or through the use of a vasectomized male. In another study [29], 83 alpacas and 11 llamas were inseminated with fresh undiluted semen collected by electro-ejaculation from one vicuna and four paco-vicunas. Semen was deposited into the uterine horns, and ovulation was induced by administration of hCG or mating with a vasectomized male. The pregnancy rate was $48 \%$ in females induced to ovulate using hCG and $11 \%$ in females induced to ovulate using a vasectomized male. More recently [15], the pregnancy rate of female alpacas inseminated with fresh semen obtained by $\mathrm{AV}$ and deposited into the uterine horns transcervically or by laparoscopy (20 per group) was 73 and $67 \%$, respectively. Similar results were reported using semen diluted with egg yolk (10\%) and citrate (3\%) by transcervical deposition and induction of ovulation with GnRH $24 \mathrm{~h}$ before AI [30]. In the most recent study [28], 51\% of 207 alpacas were diagnosed pregnant after transcervical insemination using semen collected by AV and mixed 1:1 with BSA (30\%) and glucose $(60 \%)$; ovulation was induced with a GnRH analogue (Buserelin; Intervet) 24-26 h before AI.

The absence of data on birth rates in studies done todate is disturbing, and may reflect an underlying problem related to the method and timing of inducing ovulation. In a recent study in llamas examined ultrasonographically every $4 \mathrm{~h} \mathrm{[31],} \mathrm{the} \mathrm{interval} \mathrm{from}$ ovulation-inducing stimulus (natural mating, LH, or GnRH treatment) to ovulation was $29.4 \pm 0.6 \mathrm{~h}$ and did not differ among groups. In previous studies, however, AI was done coincident with hCG treatment [15], or 24$26 \mathrm{~h}$ after GnRH treatment [28,30]. Systematic evaluation of the effects of semen extenders/handling and the timing of AI relative to ovulation are needed to determine the relative competence of the gametes to produce a normal conceptus and a live birth.

\subsection{Semen extender, cooling and freezing}

Very little information is available on the use of semen extenders in camelids (Table 3). Most extenders, as well as refrigeration and freezing techniques, used on semen of alpacas and llamas over the last $20 \mathrm{y}$ have been adopted from those developed for the bull and ram. Extenders used for llamas and alpacas have ranged from the simplest, such as sodium citrate in combination with egg-yolk, a sugar or skim milk, to a more complex media containing phosphate buffered saline, bovine serum albumin, and inorganic/organic buffers such as Tris and Hepes in combination with various sugars (lactose, fructose or glucose).

Motility of llama semen was conserved for $24 \mathrm{~h}$ postcollection when diluted with a solution of $30 \%$ BSA and $60 \%$ glucose and placed in a refrigerator [8]. Dilution with a Tris-glucose-egg yolk semen extender without elimination of viscosity resulted in poor motility (5\%) after $3 \mathrm{~h}$ [17], but results with prior mechanical liquefaction and preservation at $5{ }^{\circ} \mathrm{C}$ improved motility. Others reported the use of semen diluted with $10 \%$ egg yolk and 3\% citrate, and although no information was given about semen quality after dilution, a pregnancy rate of $60 \%$ after AI was reported [30]. In another study [32], semen collected by AV and diluted with Tris and EDTA extenders, with or without surfactant (Equex STM), was pre-warmed to $38-40{ }^{\circ} \mathrm{C}$ and maintained at that temperature until insemination; however, no pregnancies were reported.

Table 3

Results of AI in alpacas and llamas using fresh-extended or frozen* semen.

\begin{tabular}{|c|c|c|c|c|}
\hline Species [Ref.] & Semen extender & $\begin{array}{l}\text { Sperm concentration } \\
\left(10^{6} / \mathrm{mL}\right)\end{array}$ & $\begin{array}{l}\text { Diagnosed } \\
\text { pregnancy rate (\%) }\end{array}$ & Birth rate $(\%)$ \\
\hline Llama $[42]$ & Tris-citric acid- fructose & $28.9 \pm 18.7$ & 31.8 & Not reported \\
\hline Alpaca [43] & Egg-yolk-glucose citrate plus trypsin & - & 64.3 & Not reported \\
\hline Alpaca [43] & Egg-yolk-glucose citrate plus $5 \mathrm{mg} / \mathrm{mL}$ collagenase & - & 57.7 & Not reported \\
\hline Alpaca [43] & Egg-yolk-glucose citrate plus $5 \mathrm{mg} / \mathrm{mL}$ collagenase & $8-12$ & $61-67$ & Not reported \\
\hline Alpaca and Llama* [40] & Egg-yolk- citrate-glycerol plus $1 \mathrm{mg} / \mathrm{mL}$ collagenase & - & $26(5 / 19)$ & 5 \\
\hline Llama* $[41]$ & Egg-yolk-glucose plus DMSO & - & $7.8(3 / 38)$ & Not reported \\
\hline
\end{tabular}


Table 4

List of species and sub-species of threatened and extinct wild equids according to the International Union for Conservation of Nature and Natural Resources (IUCN) Red List of 2007.

\begin{tabular}{|c|c|c|c|c|c|}
\hline Genus & Species & Common name & Sub-species & Red List category & Year assessed \\
\hline Equus & burchelli & Plains zebra & $\begin{array}{l}\text { E.b. burchelli } \\
\text { E.b. antiquorum } \\
\text { E.b. chapmani } \\
\text { E.b. boehmi } \\
\text { E.b. zambeziensis } \\
\text { E.b. crawshayi }\end{array}$ & $\begin{array}{l}\text { Extinct } \\
\text { Least Concern } \\
\text { Data Deficient } \\
\text { Least Concern } \\
\text { Data Deficient } \\
\text { Data Deficient }\end{array}$ & $\begin{array}{l}1996 \\
2002 \\
1996 \\
2002 \\
1996 \\
1996\end{array}$ \\
\hline $\begin{array}{l}\text { Equus } \\
\text { Equus }\end{array}$ & $\begin{array}{l}\text { grevyi } \\
\text { zebra }\end{array}$ & $\begin{array}{l}\text { Grevy's zebra } \\
\text { Mountain zebra }\end{array}$ & $\begin{array}{l}\text { none identified } \\
\text { E. z. zebra } \\
\text { E. z. hartmannae }\end{array}$ & $\begin{array}{l}\text { Endangered } \\
\text { Endangered } \\
\text { Endangered }\end{array}$ & $\begin{array}{l}1996 \\
1996 \\
1996\end{array}$ \\
\hline Equus & africanus & African wild ass & $\begin{array}{l}\text { E. a. africanus } \\
\text { E. a. somaliensis }\end{array}$ & $\begin{array}{l}\text { Critical } \\
\text { Critical }\end{array}$ & $\begin{array}{l}1996 \\
1996\end{array}$ \\
\hline Equus & hemionus & Asiatic wild ass & $\begin{array}{l}\text { E. h. hemionus } \\
\text { E. h. hemippus } \\
\text { E. h. kulan } \\
\text { E. h. khur } \\
\text { E. h. onager } \\
\text { E. h. luteus }\end{array}$ & $\begin{array}{l}\text { Vulnerable } \\
\text { Extinct } \\
\text { Critical } \\
\text { Endangered } \\
\text { Critical } \\
\text { Vulnerable }\end{array}$ & $\begin{array}{l}2002 \\
2002 \\
2002 \\
2002 \\
2002 \\
2002\end{array}$ \\
\hline Equus & ferus & Przewalski's horse & E. f. przewalskii & Extinct in Wild & 1996 \\
\hline Equus & kiang & Kiang & $\begin{array}{l}\text { E. k. kiang } \\
\text { E. k. polyodon } \\
\text { E. k. holderi }\end{array}$ & $\begin{array}{l}\text { Data Deficient } \\
\text { Data Deficient } \\
\text { Least Risk }\end{array}$ & $\begin{array}{l}1996 \\
1996 \\
1996\end{array}$ \\
\hline
\end{tabular}

Sperm collected from the caudal epididymus has been used to avoid the complications of the viscous ejaculate, and for use in IVF. Spermatozoa from llama epididymides submitted to slow refrigeration to $5{ }^{\circ} \mathrm{C}$ after dilution with Kenney, Tris-yolk or Colorado semen extender, maintained a progressive motility of 50,30 and $20 \%$, respectively after $72 \mathrm{~h}$ [33]. In a recent alpaca study [34], epididymal alpaca spermatozoa diluted with a lactose-based extender and frozen in pellets had the highest percentage of motility and intact acrosome morphology.

Reports on the use of frozen semen are also limited (Table 3). Llama semen collected by electro-ejaculation and diluted with Tris-egg yolk- glycerol had only $10 \%$ motility after freezing and thawing [35]. Ejaculates collected from two llamas and three alpacas by AV were liquefied with collagenase $(1 \mathrm{mg} / \mathrm{mL})$ and diluted first with a mixture of sodium citrate $(2.9 \%)$ and egg yolk (10\%) and then with $7 \%$ glycerol added at $15 \mathrm{~min}$ intervals in three equal parts prior to freezing [36]. Sperm motility was estimated at $80 \%$ before freezing, $60 \%$ after final dilution and cooling (before freezing), and 30-40\% after thawing. Most recently [37], ethylene glycol was used as a cryoprotectant for alpaca semen collected by AV, liquefied by mechanical action, and diluted with skim milk and fructose. Post-thaw motility was $30 \%$ and highly correlated with estimates of live sperm and the acrosome reaction. Most studies have reported sperm motility ranging from 15 to $35 \%$ after thawing [32,38,39]. In a report of the first live births of South American camelids after AI with frozen semen [40], the semen of alpacas and llamas was treated with $1 \mathrm{mg} / \mathrm{mL}$ of collagenase, followed by a two-step dilution in sodium citrate-egg yolk extender, and frozen over liquid nitrogen vapor. After thawing, sperm motility ranged from 40 to $50 \%$, and 5/19 inseminations resulted in live births (Table 3). The inclusion of DMSO as a cryoprotectant had a negative effect on sperm motility and viability of llama semen [41].

\section{Wild equids}

The Equidae family includes the zebras, asses and horses. Although domestic and feral horses and donkeys, or burros, exist on all continents except Antarctica, wild equids are confined to the Old World (Asia and Africa). The IUCN lists seven wild species with several subspecies, the majority of which are threatened to some degree and even considered extinct in the wild (Table 4). In 2002, a Status Survey and Conservation Action Plan was published [44] that brought together the full range of what is known about 
the conservation status and biology of each of the seven species of zebras, asses and horses, including what little is known of reproductive physiology in wild equids [45].

\subsection{AI and related technologies in wild equids}

Several recent reviews [46-48] have addressed the application of reproductive technologies for the conservation of threatened and endangered species, including the use of AI. Although AI and related technologies have been used in the domestic horse industry for decades [49], the technology has only recently gained momentum for use in wild equids, in part, because of the design and development of safe and effective practices of manual restraint for handling stallions and mares on a routine basis. In species such as the Przewalski's horse (Equus ferus przewalskii), AI technology is especially important, since the current population is based on 14 founder animals. With extinction in the wild (Table 4), genetic management is critical for overall conservation of the species ex situ and in situ. Hence, AI and related technologies will facilitate breeding with founder genetics without transportation of animals, since moving and maintaining animals can be life threatening, expensive, and logistically impractical, considering that many zoological institutions are not equipped to house and manage Przewalski's stallions and other wild equid males.

A major impediment in the development of $\mathrm{AI}$ and related technologies to produce pregnancies in wild equids, is the limited knowledge base of reproductive physiology in those species. Characteristics of the estrous cycle in Przewalski's horse [50] and Grevy's zebra (Equus grevyi) [45] have been determined by monitoring hormone metabolites in urine and feces. Reproductive characteristics in other wild equids, such as Plains zebras (Equus burchelli) [51,52], Persian onagers (Equus hemionus onager) [53], and kulan (Equus hemionus kulan) [54] have been determined by observing behavior. Although reproductive ultrasonography is used routinely in domestic equids, it has had limited use in wild equids. In an early study [55], transrectal ultrasonography was used to monitor follicular development in anesthetized Przewalski's mares a few times throughout the breeding season. More recently, scientists at the Smithsonian's National Zoological Park and the Wilds have developed a technique where Przewalski's and Persian onager females can be manually restrained without anesthesia and examined using transrectal ultrasonography several times per week during the breeding season (Collins, personal communication).
Although some wild equid males have been trained to an AV for semen collection [56,57], collection of semen has been done primarily with electro-ejaculation under anesthesia. In domestic stallions, electro-ejaculation apparently has not been successful [58] and has had limited success in the Przewalski's horse $[56,59,60]$ and Persian Onager [61]. Since the latter studies involved a limited number of animals, knowledge of semen characteristics in wild equids is still rudimentary. Nonetheless, more recent progress with the use of electro-ejaculation on Przewalski's stallions has resulted in the successful collection of semen more than $85 \%$ of the time [62].

Although no pregnancies have been reported through the use of $\mathrm{AI}$ in wild equids, there is a renewed interest in conducting research in the Przewalski's horse at the Smithsonian's National Zoological Park and the Wilds using ultrasonography and reproductive hormones for synchronizing the estrous cycle and inducing ovulation for fixed-time AI with semen collected via electroejaculation. With these efforts, combined with knowledge of $\mathrm{AI}$ and related technologies gained from domestic equids, pregnancies in wild equids through the use of AI may soon be realized.

\section{Domestic equids}

The application of AI and related technologies in domestic horses has been reviewed [63-65]. Historically, studies on the collection, processing and insemination with stallion and jack semen were initiated in Russia in the late 1800s, Japan in the early 1900s, and in the United States around 1940 [66]. Although the basic concepts of collecting semen in domestic horses for $\mathrm{AI}$ are essentially unchanged since the $\mathrm{AV}$ was introduced in the 1930s, more efficient AV design as well as alternative protocols for preparing and using extenders with fresh and fresh-cooled semen are in routine use throughout the equine industry today as reviewed [67]. The following is an overview of some current areas of research in equine andrology (i.e., frozen semen, sexed semen and low-dose insemination) that have the potential to be adapted for application in wild equids.

\subsection{Frozen semen}

The first foal born from AI with frozen/thawed spermatozoa (collected from the epididymus) was in 1957 [68]. Only now, more than 50 y later, is the use of frozen semen gaining widespread use within the equine industry, because of increasing acceptance by breed 
registries and advantages over the use of fresh or freshcooled semen [63-65]. In general, pregnancy rates per cycle following AI with frozen/thawed semen are lower (range, 25-45\%) than with fresh and fresh-cooled semen (range, 20-80\%) [63]. Although there are many factors influencing pregnancy rates associated with fresh, fresh-cooled and frozen semen (e.g., semen processing and handling, reproductive health of mare, timing and site of intrauterine insemination, experience of the inseminator), the single most important factor with frozen semen appears to be the individual stallion. Spermatozoa from approximately $25 \%$ of stallions do not survive the freezing and thawing processes [69].

The nature of the "stallion effect" on freezing and thawing of spermatozoa is not well understood, but is an area of intense research. Some areas of investigation involve identifying aspects of spermatozoa and constituents of seminal plasma of different ejaculates within and among stallions during different times of the year that may be associated with cold shock, ice crystal formation, dehydration and swelling of spermatozoa during the freezing and thawing processes [49]. In addition, in vitro combined with in vivo experiments are being done to evaluate modifications to semen extenders and alternative cryoprotectants and time intervals associated with the freezing and thawing processes as well as the removal of the cyroprotectant prior to insemination. Although various methods for freezing and thawing equine spermatozoa have been described [63-65], there will likely be no standard protocols until the results of research provide a better understanding of the "stallion effect" on post-freezing survivability of equine spermatozoa.

Cryopreservation of germplasm of threatened or endangered species has been proposed as an approach to slow or halt the rate of species decline $[46,48]$. One mission under this approach is for organized repositories such as Genome or Genetic Resource Banks (GRB) to cryopreserve spermatozoa from every genetically valuable male, thus providing insurance against loss of a particular species. More immediately, AI with frozen semen would allow infusion of genetic material from free-ranging and captive animals across zoos and, perhaps, back into the wild to maintain diversity and vigor. Apparently, the only documented success of cryopreservation of spermatozoa in an endangered equid is for the "Poitou" donkey (Equus africanus assinus) [70]. This sole documentation, however, does not reflect the substantial amount of research that is ongoing with wild equids, especially the Przewalski's horse (Collins, personal communication).

\subsection{Sex-sorted semen}

The first foal born with sex-sorted semen was in 1998 [71]. Currently, the commercial application of flow cytometric sexing of equine spermatozoa is limited, primarily because of cost, time, and effort involved in the sorting and insemination processes [72]. In general, sex-sorting spermatozoa by flow-cytometry is based on the difference in DNA content between sperm carrying the $\mathrm{X}$ or $\mathrm{Y}$ chromosome. Differences in DNA content of $\mathrm{X}$ - versus Y-bearing sperm have been determined for at least 23 mammalian species, including the stallion in which an X-Y difference of $3.7 \%$ has been reported [72]. Although the accuracy of sorting X-and Y-bearing spermatozoa ranges from 85 to $95 \%$, the efficiency of sorting is relatively low. Currently, only $\sim 33 \%$ of the sperm passing through the system can be sorted to achieve a high degree of accuracy, and $\sim 20 \%$ of the sexsorted sperm are lost during the sperm concentration and packaging processes. Hence, approximately $13 \%$ of the sperm from an ejaculate are available as sorted Xand Y-bearing spermatozoa. Moreover, the current technology can only sort 1000-1500 spermatozoa/s. Hence, 4-5 d of continuous operation would be required to produce enough equine sex-sorted spermatozoa $\left(500 \times 10^{6}\right.$ progressively motile sperm $)$ for one conventional insemination dose [63-65].

Pre-selection of the sex of the offspring through the use of sex-sorted spermatozoa has great potential as a tool for breeding management and conservation of endangered wildlife, especially since re-population may be accelerated by producing predominantly female offspring [46,48]. Although sex-sorted spermatozoa has yet to be applied to wild equids, sorting of X- and Ybearing spermatozoa has been applied to other wild species (e.g., cetaceans, cervids) [46,47,72]. Although the technological process of sexing semen will continue to be optimized for domestic and non-domestic species [72], the limitation of sorting spermatozoa in high enough numbers in a reasonable amount of time has sparked renewed interest in developing low-dose insemination techniques.

\subsection{Low-dose insemination}

Three methods of insemination using unconventionally low numbers of equine spermatozoa have been developed [71,73]: (1) surgical insemination into the oviduct; (2) hysteroscopic insemination at the uterotubal junction; and (3) rectally-guided deep-intrauterine insemination near the uterotubal junction. Although with the first method pregnancies have been achieved 
with as few as 50,000-150,000 spermatozoa, it is invasive and considered impractical in most circumstances. The hysteroscopic technique is more practical, but requires specialized equipment and expertise, and at least two operators. The endoscope is guided visually without any physical manipulation of the uterus to the uterotubal junction where the spermaozoa are deposited on the oviductal papilla. The deep-intrauterine insemination technique is the most practical technique, and was initially developed for AI with sex-sorted semen. In general, the deep-intrauterine insemination procedure involves the use of a flexible pipette to negotiate the bifurcation between the left and right uterine horns. The pipette is guided by digital transrectal manipulation, and physically maneuvered to the cranial aspect of the uterine horn ipsilateral to the preovulatory follicle where the spermatozoa are deposited near the papilla.

Typically, AI with frozen equine semen using these techniques involves a volume of $0.5 \mathrm{~mL}$ with 50 $100 \times 10^{6}$ spermatozoa. With the hysteroscopic technique, however, higher pregnancy rates were reported with $3 \times 10^{6}$ versus $14 \times 10^{6}$ frozen-thawed spermatozoa [74]. Although there is a need to directly compare the efficacy of the hysteroscopic and deep-intrauterine AI techniques using frozen semen, a relatively recent study has compared the two techniques with sexed equine semen [75]. Insemination with $20 \times 10^{6}$ pre-cooled, sexsorted spermatozoa resulted in pregnancy rates from 55 to $72 \%$ using the hysteroscopic AI technique compared to a pregnancy rate of $38 \%$ using the deep-intrauterine $\mathrm{AI}$ technique. However, hysteroscopy is more complicated in wild equids, primarily because of time and effort associated with general anesthesia. The deep-intrauterine insemination technique is more readily applicable and has been used recently with Przewalski's mares (Collins, personal communication).

\section{Conclusion}

Difficulties with semen collection, dilution and cryopreservation have limited the development and use of AI in camelid species. However, progress has been made and viable offspring have been produced through the use of $\mathrm{AI}$ in domestic camelids, using both fresh and frozen semen. A better understanding of the normal constituents of seminal plasma will enable the rational design of semen extenders suitable for camelids. The origin, composition, and function of the viscous component of camelid seminal plasma remain a mystery and an obvious area for future research. To improve efficiency and maximize the use of valuable males, studies are also needed to address questions of optimal freezing and thawing procedures and insemination dose. The basis for differences in reported pregnancy rates with sexed and frozen semen in domestic equids, and the ultimate success of $\mathrm{AI}$ in wild equids, will require continued research into the "stallion effect", extenders and cryoprotectants, optimal volume and number of spermatozoa, temperatures during handling, processing and transport, and insemination techniques. In both camelids and equids, research on domestic species under controlled conditions provides an excellent opportunity to develop effective semen handling techniques for application in wild and endangered species of the respective families.

\section{References}

[1] Fernandez-Baca S, Novoa C. Primer ensayo de Inseminación Artificial de alpacas (Lama paco) con semen de vicuña (Vicugna-vicugna). Rev. Facultad de Medicina VeterinariaUNMSM, Lima, Perú 1968; 2:9-18.

[2] Lichtenwalner AB, Woods GL, Weber JA. Ejaculatory patterns of llamas during copulation. Theriogenology 1996;46:285-91.

[3] Mogrovego D. Estudios del semen de la alpaca. BS Thesis. Facultad de Medicina Veterinaria, Universidad Nacional Mayor de San Marcos, Lima, Peru 1952; 21 p.

[4] San Martin M. Fisiología de la reproducción de la Alpaca. Animal Symposio Sobre Problemas Ganaderos. Lima, Perú 1961; 113-31.

[5] Von Kubicek J. Semen collection in alpaca with a urethral fistula (German). Zeitschrift Tierzuchtung und Zuchtungsbiologie 1974;90:335-51.

[6] Sumar J, Leyva V. Coleccion de semen mediante vagina artificial en la alpaca. In: Proceedings of the 4th International Conference on South America Camelids, Punta Arenas, Chile; 1981.p. 12.

[7] Gauly M, Leindinger H. Semen quality, characteristics volume distribution and hypo-osmotic sensitivity of spermatozoa of Lama glama and Lama guanicoe. In: Gerken M, Renieri C, editors. Proceedings of the 2nd European Symposium on South American Camelids. 1996. p. 235-44.

[8] Huanca W, Gauly M. Conservacion de semen refrigerado de 1lamas. Rev Inv Vet Peru 2001;1:460-1.

[9] Fernandez-Baca S, Calderon W. Metodos de colección de semen de la alpaca. Rev Facultad de Medicina Veterinaria-Universidad Nacional Mayor de San Marcos, Lima, Peru 1966; 13:18-20.

[10] Calderon W, Sumar J, Franco E. Avances en la Inseminación artificial de las alpacas (Lama paco). Rev Facultad de Medicina Veterinaria 1968;22:19-35.

[11] Giuliano S, Director A, Gambarotta M, Trasorras V, Miragaya M. Collection method, season and individual variation of seminal characteristics in Lama glama. Anim Reprod Sci 2008; 104:359-69.

[12] Giuliano SM, Spirito SE, Miragaya MH, Capdevielle EF, Aguero A, Boquet MD, et al. Electroejaculation and seminal parameters in vicuna (Vicugna vicugna). Theriogenology 2002;57:583.

[13] Garnica J, Achata R, Bravo PW. Physical and biochemical characteristics of alpaca semen. Anim Reprod Sci 1993;32:85-90.

[14] Garnica J, Flores E, Bravo PW. Citric acid and fructose concentrations in seminal plasma of alpaca. Small Rum Res 1995;18:95-8. 
[15] Bravo PW, Flores U, Garnica J, Ordonez C. Collection of semen and artificial insemination of alpacas. Theriogenology 1997;47: 619-26.

[16] Sumar J, García M. Fisiologia de la reproduccion de la alpaca. In: Nuclear and Related Techniques in Animal Production and Health. Vienna: IAEA; 1986. p. 149-77.

[17] Raymundo F, Huanca W, Huertas S, Gauly M. Influence of different extenders on the motility in alpaca (Lama pacos) semen. In: Proceedings of the 2nd International Camelid Conference-Agroeconomics of Camelid Farming; 2000.p. 79.

[18] Bravo PW, Callo M, Garnica J. The effect of enzymes on semen viscosity in llamas and alpacas. Small Rum Res 2000;38:91-5.

[19] Flores P, Garcia-Huidobro J, Munoz C, Bustos-Obregon E, Urquieta B. Alpaca semen characteristics previous to a mating period. Anim Reprod Sci 2002;72:259-66.

[20] Huanca W, Adams GP. Semen collection and artificial insemination in llamas and alpacas. In: Youngquist RS, Threlfall WR, editors. Current therapy in large animal theriogenology. 2nd ed., St. Louis MO: Saunders Elsevier; 2006. p. 869-73.

[21] Lichtenwalner AB, Woods GL, Weber JA. Seminal collection, seminal characteristics and pattern of ejaculation in llamas. Theriogenology 1996;46:293-305.

[22] Von Baer L, Hellemann C. Variables seminales en llama (Lama glama). Arch Med Vet 1998;30:171-6.

[23] Bravo PW, Flores D, Ordonez C. Effect of repeated collection on semen characteristics of alpacas. Biol Reprod 1997;57:520-4.

[24] Fernandez Baca S. Manipulation of reproductive functions in male and female New World camelids. Anim Reprod Sci 1993;33:307-23.

[25] Mattner PE, Braden AW. Comparison of the distribution of motile and nonmotile spermatozoa in the ovine cervix. Aust $\mathrm{J}$ Biol Sci 1969;22:1069-70.

[26] Maxwell CWM, Evans G, Morton KM. The development of collection, processing and storage technologies for alpaca semen. In: Proceedings, International Congress on Animal Reproduction Satellite Symposium on Camelid Reproduction; 2008. p. 19-22.

[27] Valdivia M, Ruiz M, Bermúdez L, Quinteros S, Gonzales A, Manosalva I, et al. Criopreservacion de semen de alpacas.. In: Proceedings of the 2nd Congreso Mundial Sobre Camelidos; 1999.p. 81 .

[28] Apaza N, Sapana R, Huanca T, Huanca W. Inseminación artificial en alpacas con semen fresco en comunidades campesinas. Rev Invest Vet Suppl 2001;1:435-8.

[29] Leyva V, Franco E, Sumar J. Inseminación Artificial en camelidos sudamericanos. In: Proceedings, I Reunion Ciedntifica Anual de Asociación Peruana de Producción Animal (APPA) Lima; 1977.p. 21.

[30] Pacheco C. Efecto de la tripsina y colagenasa sobre el acrosoma del espermatozoide y su relacion con la fertilidad del semen de alpaca. Thesis MVZ Programa Medicina Veterinaria y Zootecnia, Universidad Catolica de Santa Maria, Arequipa, Peru 1996; 52.

[31] Ratto MH, Huanca W, Singh J, Adams GP. Comparison of the effect of natural mating, $\mathrm{LH}$, and $\mathrm{GnRH}$ on interval to ovulation and luteal function in llamas. Anim Reprod Sci 2005;91:299306.

[32] Von Baer L, Hellemann C. Cryopreservation of llama semen. Reprod Dom Anim 1999;34:95-6.

[33] Ratto MH, Wolter M, Berland M. Refrigeration of epididymal sperm from lama with three different extenders. In: Proceedings of the 2nd Congreso Mundial Sobre Camelidos; 1999.p. 79.
[34] Morton K, Bathgate R, Evans G, Maxwell WMC. Cryopreservation of epididymal alpaca (Vicugna pacos) sperm: a comparison of citrate-Tris- and lactose-based diluents and pellets and straws. Reprod Fert Devel 2007;19:792-6.

[35] McEvoy TG, Kyle CE, Slater D, Adam CL, Bourke DA. Collection evaluation and cryopreservation of llama semen. $\mathrm{J}$ Reprod Fert 1992;9:48.

[36] Bravo PW, Flores U, Garnica J, Ordóñez C. Processing and freezing semen of alpacas and llamas. In: Proceedings of the 13th International Congress on Animal Reproduction; 1996. p. 2-3.

[37] Santiani A, Huanca Sapana WR, Huanca T, Sepúlveda N, Sánchez R. Effects on the quality of frozen-thawed alpaca (Lama pacos) semen using two different cryoprotectants and extenders. Asian J Androl 2005;7:303-9.

[38] Burgel H, Erhardt G, Gauly M. Cryopreservation of llama (Lama glama) semen. In: Proceedings of the 2nd Congreso Mundial Sobre Camelidos; 1999.p. 82.

[39] Vaughan JL, Galloway D, Hopkins D. Artificial insemination in alpacas (Lama pacos). Pub. No. 03/104. RIRDC Rural industries Research and Development Corporation, Kingston, Australia 2003; 67-73.

[40] Bravo PW, Skidmore JA, Zhao XX. Reproductive aspects and storage of semen in camelidae. Anim Reprod Sci 2000;62:17393.

[41] Aller JF, Rebuffi G, Cancino AK, Alberio RH. Influencia de la criopreservacion sobre la motilidad, viabilidad y fertilidad de espermatozoides de llama (Lama glama). Arch Zootec 2003;152:15-23.

[42] Aller JF, Cancino AK, Rebuffi G, Alberio RH. Inseminacion artificial en llamas en la Puna. In: Proceedings of the 2nd Congreso Mundial Sobre Camelidos; 1999.p. 72.

[43] Bravo PW, Pacheco C, Quispe G, Vilcapaza L, Ordonez C. Degelification of alpaca semen and the effect of dilution rates on artificial insemination outcome. Archiv Androl 1999;43:239-46.

[44] Conservation Action Plan. IUCN/SCC Equid Specialist Group, IUCN, Gland, Switzerland and Cambridge, UK, 2002; 1-190.

[45] Asa CS. Equid reproductive biology. In: Moehlman PD, editor. Equids: Zebras, Asses, and Horses. Status Survey and Conservation Action Plan. IUCN/SCC Equid Specialist Group, IUCN, Gland, Switzerland and Cambridge, UK 2002; 113-7.

[46] Pukazhenthi BS, Wildt DE. Which reproductive technologies are most relevant to studying, managing and conserving wildlife. Reprod Fertil Develop 2004;16:33-46.

[47] Pukazhenthi BS, Comizzoli P, Travis AJ, Wildt DE. Applications of emerging technologies to the study and conservation of threatened and endangered species. Reprod Fertil Develop 2006; 18:77-90.

[48] Andrabi SMH, Maxwell WMC. A review on reproductive biotechnologies for conservation of endangered mammalian species. Anim Reprod Sci 2007;99:223-43.

[49] Squires EL. Integration of future biotechnologies into the equine industry. Anim Reprod Sci 2005;89:187-98.

[50] Monfort SL, Arthur NP, Wildt DE. Monitoring ovarian function and pregnancy by evaluating excretion of urinary oestrogen conjugates in semi-free-ranging Przewalski's horses (Equus przewalksii). J Reprod Fertil 1991;91:155-64.

[51] Schilder MBH, Baer PL. Ethological investigations on a herd of plains zebra in a safari park: time budgets, reproduction, and food competition. Appl Anim Behav Sci 1987;18:45-56.

[52] Pluháček J, Luděk B, Luděk C. High ranking mares of captive plains zebra (Equus burchelli) have greater reproductive success than low-ranking mares. Appl Anim Behav Sci 2006;99:315-29. 
[53] Klingel H. Observations and behavior of African and Asiatic wild asses (equus africanus and equus hemionus). App Anim Behav Sci 1998;60:103-13.

[54] Bahloul K, Pereladova OB, Soldatova N, Fiseako G, Siderenko E, Sémpéré AJ. Social organization and dispersion of introduced kulans (Equus hemionus kulan) and Przewalski's horses (Equus przewalskii) in the Burkhara reserve, Uzbekistan. J Arid Env 2001;47:309-33.

[55] Durrant BS, Oosterhuis JE, Hoge ML. The application of artificial reproduction techniques to the propagation of selected endangered species. Theriogenology 1986;25:25-32.

[56] Bader H, Gremmes S, Sieme H, Paar M, Hoppen HO, Brandt KP. Subfertility in the male Przewalski horse. J Reprod Fertil Suppl 1991;44:676-7.

[57] Crump Jr JP, Crump JW. Manual semen collection from a Grevy's zebra stallion (Equus grevyi), onset of sperm production, semen characteristics, and cryopreservation of semen, with a comparison to the sperm production from a Grant's Zebra stallion (Equus burchelli boehmi). Theriogenology 1994;41: 1011-21.

[58] Cary JA, Madill S, Farmsworth K, Hayma JT, Ducos L, Fahning ML. A comparison of electroejaculation and epididymal sperm collection techniques in stallions. Can Vet J 2001;45:35-41.

[59] Stover J, Seager SWJ, Dolensk EP, Doherty J, Wildt DF, Platz CC. Electroejaculation and semen evaluation of the Przewalski Horse (Equus przewalski). Am Assoc Zoo Vet 1981;144-5.

[60] Durrant BS. Semen characteristics of the Przewalski's stallion (Equus przewalski). Theriogenology 1990;33:221.

[61] Howard JG, Parsel VG, Wildt DE, Bush M. Comparison of various extenders for freeze-preservation of semen from selective captive wild ungulates. J Am Vet Med Assoc 1981;179:1157-61.

[62] Collins CW, Songsasen N, Monfort SL, Bush M, Wolfe B, James $\mathrm{SB}$, et al. Seminal traits in the Przewalski's horse (Equus ferus przewalskii) following electroejaculation. Anim Reprod Sci 2006;94:46-9.

[63] Frazer GS. Reproduction. In: Edward Robinson N, editor. Current therapy in equine medicine,. 5th ed., Philadelphia: Saunders; 2003. p. 226-334.
[64] Samper JC, Pycock JF, McKinnon AO. Current therapy in equine reproduction. St. Louis: Saunders/Elsevier; 2007. p. 167-334.

[65] Youngquist RS, Threlfall WR. Equine theriogenology. In: Current therapy in large animal theriogenology. St. Louis: Saunders/ Elsevier; 2007. p. 3-218.

[66] Foote RH. The history of artificial insemination: selected notes and notables. J Anim Sci 2002;80:1-10.

[67] Samper JC. Equine breeding management and artificial insemination.. Philadelphia: WB Saunders; 2000. pp. 1-140.

[68] Barker CAV, Gandier JCC. Pregnancy in a mare resulted from frozen epididymal spermatozoa. Can J Comp Med Vet Sci 1957;21:45-51.

[69] Squires EL. Future equine reproductive technologies. In: Samper JC, editor. Equine breeding management and artificial insemination. 1st ed., Philadelphia: WB Saunders; 2000. p. 283-306.

[70] Trimeche A, Renard P, Tainturier D. A procedure for Poitou jackass sperm cryopreservation. Theriogenology 1998;50:793806.

[71] Vanderwall DK, Woods GL. Embryo transfer and newer assisted reproducutive techniques for horse. In: Youngquist RS, Threlfall WR, editors. Current therapy in large animal theriogenology. St. Louis: Saunders/Elsevier; 2007. p. 211-8.

[72] Garner DL. Flow cytometric sexing of mammalian sperm. Theriogenology 2006;65:943-97.

[73] Matthews P, Morris L. Low-dose insemination techniques. In: Samper JC, Pycock JF, McKinnon AO, editors. Current therapy in equine reproduction. St. Louis: Saunders/Elsevier; 2007. p. 315-8.

[74] Morris LHA, Tiplady CA, Allen WR. Pregnancy rates in mares after a single fixed time hysteroscopic insemination with low numbers of frozen-thawed spermatozoa onto the uterotubal junction. Equine Vet J 2003;35:197-201.

[75] Lindsey AC, Varner DD, Seidel Jr GE, Bruemmer JE, Squires EL. Hysteroscopic or rectally guided, deep-uterine insemination of mares with spermatozoa stored $18 \mathrm{~h}$ at either $5{ }^{\circ} \mathrm{C}$ or $15^{\circ} \mathrm{C}$ prior to flow-cytometric sorting. Anim Reprod Sci 2005;85: $125-30$. 